SCIENTIFIC REPORT

\title{
Photodynamic therapy of circumscribed choroidal haemangioma
}

\author{
A D Singh, P K Kaiser, J E Sears, M Gupta, P A Rundle, I G Rennie
}

Br J Ophthalmol 2004;88:1414-1418. doi: 10.1136/bjo.2004.044396

Aim: To evaluate efficacy of verteporfin ocular photodynamic therapy (PDT) in treatment of 10 patients with a symptomatic circumscribed choroidal haemangioma.

Design: Prospective non-randomised, interventional case series and critical review of previously published studies.

Methods: 10 consecutive patients (seven primary, two failed transpupillary thermotherapy (TTT), and one failed external beam radiotherapy) with symptomatic circumscribed choroidal haemangioma were treated using verteporfin $6 \mathrm{mg} / \mathrm{m}^{2}$ given as an intravenous infusion over 10 minutes. Diode laser $(690 \mathrm{~nm})$ with an intensity of $600 \mathrm{~mW} / \mathrm{cm}^{2}$ for 83 seconds $\left(50 \mathrm{~J} / \mathrm{cm}^{2}\right)$ was applied 5 minutes after completion of infusion. Single or multiple partially overlapping spots were applied based on the tumour basal dimensions. Periodic follow up with ophthalmoscopy, ultrasonography, and angiographic studies was performed.

Results: All 10 patients showed evidence of regression with flattening of tumour, resolution of subretinal fluid, and reduction of choroidal vasculature on angiograms. The visual acuity either improved or remained stable in eight (80\%) patients. Visual loss due to delayed choroidal atrophy was seen in two patients.

Conclusions: Although verteporfin PDT is an effective treatment for management of symptomatic circumscribed choroidal haemangioma, delayed treatment related effects can lead to visual loss.

C horoidal haemangioma is an uncommon benign vascular tumour of the choroid that can be either circumscribed or diffuse. ${ }^{1}$ Choroidal haemangiomas are usually diagnosed between the second to the fourth decade of life when they cause visual disturbance due to exudative retinal detachment. ${ }^{2}$ The long term visual prognosis is poor even in adequately treated patients. ${ }^{3}$

Circumscribed choroidal haemangioma can be treated with laser photocoagulation, ${ }^{4}$ cryotherapy, ${ }^{5}$ external beam radiotherapy, ${ }^{67}$ stereotactic radiotherapy, ${ }^{8}$ proton beam radiotherapy, ${ }^{9}$ episcleral plaque radiotherapy, ${ }^{3}$ and transpupillary thermotherapy (TTT). ${ }^{10}$ These treatments are associated with the potential risk of damage to the overlying retina.

Conceptually, ocular photodynamic therapy (PDT) with verteporfin would seem to appear an ideal method for the treatment of circumscribed choroidal haemangiomas as it can offer site specific tumour destruction while sparing overlying retina and retinal vasculature ${ }^{11}$ and has been reported as the initial method of treating circumscribed choroidal haemangiomas. ${ }^{12-15}$ Encouraged by favourable initial published results (table 1$)^{12-19}$ and our own preliminary experience on three patients, ${ }^{20}$ we have continued to perform PDT in 10 patients with a symptomatic circumscribed choroidal haemangioma as part of an ongoing prospective interventional study.

\section{METHODS}

Patients were included in this clinical study if they had a symptomatic circumscribed choroidal haemangioma and gave informed consent to off-label treatment with verteporfin ocular PDT. All vascular tumours are analysed by fundus photography, angiographic studies, and A-scan and B-scan ultrasonography. The uniform standard protocol treatment regimen (TAP Study protocol) for administration and activation of verteporfin was followed in all patients. ${ }^{21}$ All patients were given $6 \mathrm{mg} / \mathrm{m}^{2}$ of verteporfin as an intravenous infusion over 10 minutes. Five minutes after the completion of the infusion, PDT was performed with a diode laser $(690 \mathrm{~nm})$ with an intensity of $600 \mathrm{~mW} / \mathrm{cm}^{2}$ for exposure of 83 seconds $\left(50 \mathrm{~J} / \mathrm{cm}^{2}\right)$. Single or multiple partially overlapping spots were applied to cover the entire surface of the tumour in a single session based on tumour basal dimensions. A second session of treatment was applied in two patients because of partial response, 4 and 6 months after the initial treatment respectively. Periodic follow up at 1 month, 3 month, and every 6 months thereafter was carried out.

\section{RESULTS}

All 10 consecutive patients were white. There were six males and four females. The median age at diagnosis was 53 years (range $25-73$ years). All 10 patients were symptomatic as a result of circumscribed choroidal haemangioma located in the juxtapapillary region (two patients), foveal region (seven patients) and extrafoveal region (one patient) causing subretinal fluid exudation. Three patients had been previously unsuccessfully treated with TTT (two patients) and external beam radiotherapy (one case) (table 2). Seven other patients underwent primary treatment with PDT. The median pre-PDT tumour basal diameter was $7.5 \mathrm{~mm}$ (range $6.0 \mathrm{~mm}-$ $9.5 \mathrm{~mm}$ ) and height was $2.5 \mathrm{~mm}$ (range $1.9 \mathrm{~mm}-5.8 \mathrm{~mm}$ ). Five minutes after the completion of the infusion, a single spot of $5800 \mu \mathrm{m} \quad\left(600 \mathrm{~mW} / \mathrm{cm}^{2}, 50 \mathrm{~J} / \mathrm{cm}^{2}\right.$, exposure of 83 seconds) was applied in one case. The remaining nine cases were treated with multiple (4-8) partially overlapping spots ranging in size from $2500-4000 \mu \mathrm{m}$ applied to cover the entire surface of the tumour in a single session. Following PDT, there was marked reduction in tumour height with eight tumours appearing completely flat and two with residual thickness of $1.5 \mathrm{~mm}$ (fig 1 ). Two patients underwent two sessions of PDT, 4-6 months following initial PDT because of partial response following the first session of PDT. Both tumours appeared completely regressed following the second session of PDT (fig 2). Angiographic studies revealed prominent reduction of tumour vasculature with sparing of overlying retinal vessels (figs 1 and 2).

Abbreviations: PDT, photodynamic therapy; TT, transpupillary thermotherapy 
Table 1 Published reports of photodynamic therapy of circumscribed choroidal haemangioma*

\begin{tabular}{|c|c|c|c|c|c|c|c|c|c|c|}
\hline \multirow[b]{2}{*}{ Author } & \multirow[b]{2}{*}{ Year } & \multirow[b]{2}{*}{$\begin{array}{l}\text { No of } \\
\text { eyes }\end{array}$} & \multirow[b]{2}{*}{$\begin{array}{l}\text { Primary or } \\
\text { secondary }\end{array}$} & \multirow[b]{2}{*}{$\begin{array}{l}\text { Median follow } \\
\text { up (range) } \\
\text { months }\end{array}$} & \multicolumn{3}{|c|}{ Method of treatment } & \multicolumn{2}{|c|}{ Results eyes (\%) } & \multirow[b]{2}{*}{$\begin{array}{l}\text { Complications } \\
\text { (eyes) }\end{array}$} \\
\hline & & & & & Protocol & Spots & Sessions & $\begin{array}{l}\text { Tumour } \\
\text { regression }\end{array}$ & $\begin{array}{l}\text { Vision } \\
\text { improved } \\
\text { or stable }\end{array}$ & \\
\hline Barbazetto $^{12}$ & 2000 & 2 & $2 / 0$ & $11(9-12)$ & $\begin{array}{l}\text { Standard } 100 \\
\mathrm{~J} / \mathrm{cm}^{2} 168 \mathrm{~s}\end{array}$ & $\geqslant 1$ Overlapping & $2-4$ & $2(100 \%)$ & $2(100 \%)$ & None \\
\hline Madreperla ${ }^{13}$ & 2001 & 3 & $3 / 0$ & $4(3-9)$ & Standard & 1 & 1 & $3(100 \%)$ & $3(100 \%)$ & None \\
\hline Robertson ${ }^{14}$ & 2002 & 3 & $3 / 0$ & $13(11-14)$ & Standard $†$ & $\geqslant 1$ Overlapping & $1-2$ & $3(100 \%)$ & $3(100 \%)$ & None \\
\hline $\begin{array}{l}\text { Schmidt- } \\
\text { Erfurth }^{15}\end{array}$ & 2002 & 15 & $15 / 0$ & $19(12-50)$ & $\begin{array}{l}\text { Bolus (1 min) } \\
100 \mathrm{~J} / \mathrm{cm}^{2} \\
166 \mathrm{~s}\end{array}$ & 1 & $1-4$ & $15(100 \%)$ & $15(100 \%)$ & None \\
\hline $\operatorname{Landau}^{16}$ & 2002 & 8 & $4 / 4$ & $7(3-15)$ & Standard & $\geqslant 1(?)$ & $1-2$ & $7(88 \%)$ & $7(88 \%)$ & $\begin{array}{l}\text { Choroidal effusion } \\
\text { and perifoveal } \\
\text { haemorrhage (1) }\end{array}$ \\
\hline Jurklies $^{17}$ & 2003 & 19 & $15 / 4$ & $11(2-24)$ & $\begin{array}{l}\text { Bolus (2 min) } \\
100 \mathrm{~J} / \mathrm{cm}^{2} \\
166 \mathrm{~s}\end{array}$ & $\begin{array}{l}\geqslant 1 \text { non- } \\
\text { overlapping }\end{array}$ & $1-5$ & $19(100 \%)$ & $18(95 \%)$ & None \\
\hline Verbraak $^{18}$ & 2003 & 13 & $11 / 2$ & $12(3-22)$ & $\begin{array}{l}\text { Bolus (1 min) } \\
50-100 \mathrm{~J} / \mathrm{cm}^{2} \\
83-166 \mathrm{~s}\end{array}$ & 1 & $1-2$ & $13(100 \%)$ & 13 (100\%) & None \\
\hline Porrini $^{19}$ & 2003 & 10 & $7 / 3$ & $13(7-16)$ & $\begin{array}{l}\text { Standard 75- } \\
100 \mathrm{~J} / \mathrm{cm}^{2} \\
125-186 \mathrm{~s} /\end{array}$ & 1 & $1-3$ & $10(100 \%)$ & 10 (100\%) & None \\
\hline Present study & 2004 & 10 & $7 / 3$ & $7(1-13)$ & Standard & $\geqslant 1$ Overlapping & $1-2$ & $10(100 \%)$ & $8(80 \%)$ & Choroidal atrophy (2) \\
\hline
\end{tabular}

Standard: 10 minute infusion of $6 \mathrm{mg} / \mathrm{m}^{2}$ verteporfin, laser application 5 minute after completion of infusion and laser settings; power $=50 \mathrm{~J} / \mathrm{cm}^{2}$, intensity $=$ $600 \mathrm{~mW} / \mathrm{cm}^{2}$, duration $=83$ seconds.

*Excluding single case reports.

†Laser application 10 minute after completion of infusion.

The median pre-PDT visual acuity was 20/30 (range 20/30$20 / 400$ ) and median post-PDT visual acuity was 20/30 (range 20/20-20/200). The visual acuity improved in four patients $(40 \%)$, remained unchanged in four patients $(40 \%)$, and deteriorated in two $(20 \%)$ patients. The deterioration of vision in both patients that occurred following PDT was attributed to choroidal atrophy. In one patient (patient 6) it was noted within the first month following PDT and it remained unchanged thereafter. The second patient (patient 7) had initial marked improvement of vision from 20/100 to 20/30 but after about 12 months lost vision $(20 / 100)$ as a result of choroidal and retinal pigment epithelial atrophy (fig 3).

\section{DISCUSSION}

The decision to treat choroidal haemangioma should be individualised based upon the extent of symptoms, loss of vision, and potential for visual recovery. The aim of treatment is to induce sufficient tumour atrophy with resolution of subretinal fluid and tumour induced foveal distortion without destroying the function of the overlying retina. Compared to previously reported methods of treatment for choroidal haemangioma,
PDT offers a potential of sparing overlying retina and retinal vessels. Moreover, it can be conveniently performed as an outpatient procedure under topical anaesthesia.

Excellent anatomical and functional results from all published studies are summarised in table 1. The total experience of treating circumscribed choroidal haemangioma involves fewer than 75 patients who have been followed for a relatively short period. The technique of treatment is varied between different investigators with some $^{13} 1619$ infusing verteporfin over 10 minutes similar to the treatment guidelines for age related macular degeneration. ${ }^{21}$ Others have argued in favour of using a bolus injection to compensate for altered haemodynamics within the choroidal haemangioma. ${ }^{12}{ }^{15} 1718$ We have preferred to use the standard TAP study protocol rather than a bolus injection because of greater experience with TAP study protocol and equally good results obtained in patients treated with either protocols.

The other variables in the treatment have included the number of treatment sessions (1-5), laser power settings (50-100 J), duration of exposure (83-186 seconds), and

Table 2 Summary of clinical findings of 10 patients with circumscribed choroidal haemangioma treated with photodynamic therapy

\begin{tabular}{|c|c|c|c|c|c|c|c|c|c|c|}
\hline \multirow[b]{3}{*}{ Patient } & \multirow{3}{*}{$\begin{array}{l}\text { Age } \\
\text { (years) }\end{array}$} & \multirow[b]{3}{*}{ Sex } & \multirow{3}{*}{$\begin{array}{l}\text { Previous } \\
\text { treatment }\end{array}$} & \multicolumn{3}{|c|}{ Pretreatment } & \multicolumn{3}{|c|}{ Post-treatment } & \multirow[b]{3}{*}{ Comments } \\
\hline & & & & \multicolumn{2}{|c|}{ Size (mm) } & \multirow{2}{*}{$\begin{array}{l}\text { Visual } \\
\text { acuity }\end{array}$} & \multirow{2}{*}{$\begin{array}{l}\text { Height } \\
\text { (mm) }\end{array}$} & \multirow{2}{*}{$\begin{array}{l}\text { Visual } \\
\text { acuity }\end{array}$} & \multirow{2}{*}{$\begin{array}{l}\text { Follow up } \\
\text { (months) }\end{array}$} & \\
\hline & & & & Base & Height & & & & & \\
\hline 1 & 73 & $\mathrm{~F}$ & None & 11 & 3 & $20 / 40$ & 1.5 & $20 / 30$ & 1 & \\
\hline 2 & 73 & $M$ & None & 7.5 & 3.5 & $20 / 30$ & 1.5 & 2030 & 4.5 & \\
\hline 3 & 50 & $M$ & TाT & 6 & 1.9 & $20 / 80$ & 0 & $20 / 60$ & 12 & \\
\hline 4 & 58 & $\mathrm{~F}$ & TाT & 6 & 2.5 & $20 / 30$ & 0 & $20 / 20$ & 1 & \\
\hline 5 & 36 & $M$ & EBRT & 11 & 5.8 & $20 / 30$ & 0 & $20 / 30$ & 6 & \\
\hline 6 & 25 & $\mathrm{~F}$ & None & 7.5 & 2.4 & $20 / 30$ & 0 & $20 / 200$ & 2 & Choroidal atrophy \\
\hline 7 & 52 & $\mathrm{~F}$ & None & 6 & 2.5 & $20 / 100$ & 0 & $20 / 100$ & 12 & Choroidal atrophy \\
\hline 8 & 34 & $M$ & None & 7 & 2.5 & $20 / 40$ & 0 & $20 / 40$ & 8 & \\
\hline 9 & 66 & $M$ & None & 7.5 & 2.5 & $20 / 30$ & 0 & $20 / 30$ & 13 & 2 Sessions \\
\hline 10 & 55 & $M$ & None & 9.5 & 2.5 & $20 / 400$ & 0 & $20 / 80$ & 13 & 2 Sessions \\
\hline
\end{tabular}

TIT, transpupillary thermotherapy; EBRT, external beam radiotherapy.

*Recurrence: retreated with second session of photodynamic therapy 7 months after the initial therapy. 

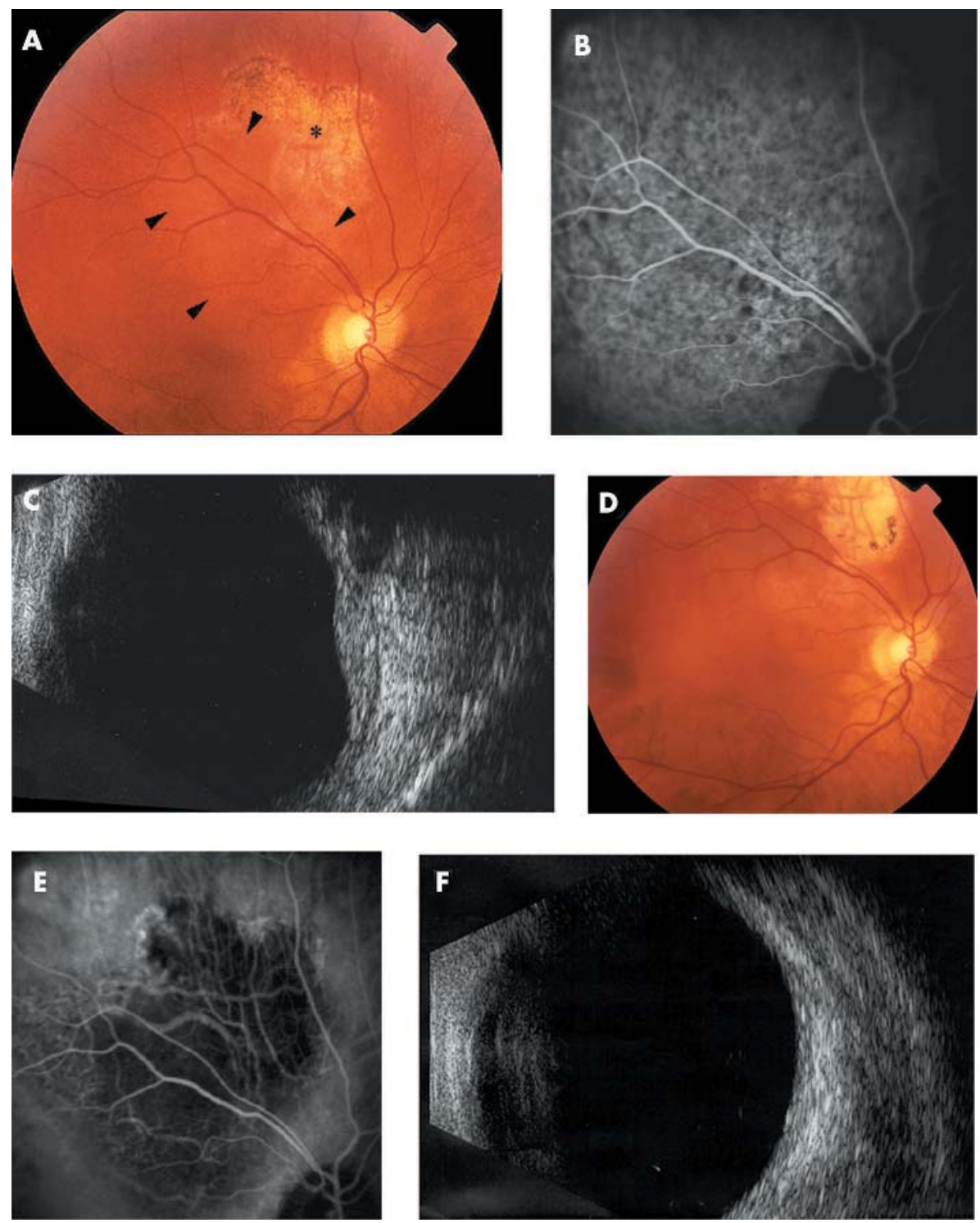

Figure 1 (A) Fundus photograph of the right eye showing a circumscribed choroidal haemangioma (arrowheads). The tumour was unsuccessfully treated with transpupillary thermotherapy $\left(^{*}\right)$. (B) Indocyanine green angiogram showing choroidal hypervascularity and hyperfluorescence due to choroidal haemangioma. (C) B-scan ultrasonograph of a dome shaped choroidal lesion and high internal reflectivity (thickness $2.5 \mathrm{~mm}$ ). (D) Posttreatment fundus appearance showing regression of haemangioma. Areas of retinal pigment epithelial stippling and atrophy are present in the treated areas. (E) Post-treatment indocyanine green angiogram demonstrating that the choroidal haemangioma is replaced by an area of hypovascular choroid. (F) Post-treatment B-scan ultrasonograph showing marked regression of the choroidal haemangioma.

number of spots (one or more) applied. Satisfactory regression of choroidal haemangioma in three patients with one session of PDT was initially demonstrated by Madreperla ${ }^{13}$ and we have observed similar preliminary results. ${ }^{20}$ In general, the tumour regression is most dramatic following the first session of $\mathrm{PDT}^{15}$ and is evident within 3 months. ${ }^{13}$ Additional PDT may be considered after 3 months if the tumour or subretinal fluid persists. ${ }^{19}$ The number of PDT sessions should be kept to minimum as the number of PDT treatment sessions may be inversely related to the final visual acuity. ${ }^{17}$

Laser power settings to deliver a radiant exposure of 50$100 \mathrm{~J} / \mathrm{cm}^{2}$ at an irradiance of $600 \mathrm{~mW} / \mathrm{cm}^{2}$ over $83-$ 166 seconds are considered safe and effective. ${ }^{15}$ These recommendations are based on studies of choroidal neovascular membranes treated by PDT. ${ }^{11}$

There is significant potential for choroidal atrophy following PDT as observed by Schmidt-Erfurth ${ }^{15}$ and noted in two patients from our series. It appears that the technique of spot application on the tumour surface is critical to avoid the complication of choroidal atrophy. Although multiple overlapping spots have been initially used, ${ }^{12}{ }^{14}$ the majority of the investigators have used either a single $\operatorname{spot}^{1315161819}$ or multiple but non-overlapping spots. ${ }^{17}$ Other means to minimise the risk of choroidal atrophy is to keep the spot size small so as to exclude normal surrounding choroid from the exposure ${ }^{15}$ and to avoid re-exposure of the previously treated portions of the tumour. ${ }^{15} 19$

In summary, verteporfin PDT of circumscribed choroidal haemangioma is effective in inducing tumour regression in almost all cases and improving or stabilising vision in the majority of patients. Overtreatment with PDT has the potential for causing choroidal atrophy resulting in significant visual loss but can be avoided by using either a single spot or multiple non-overlapping spots and by excluding surrounding normal choroid during treatment planning. PDT 

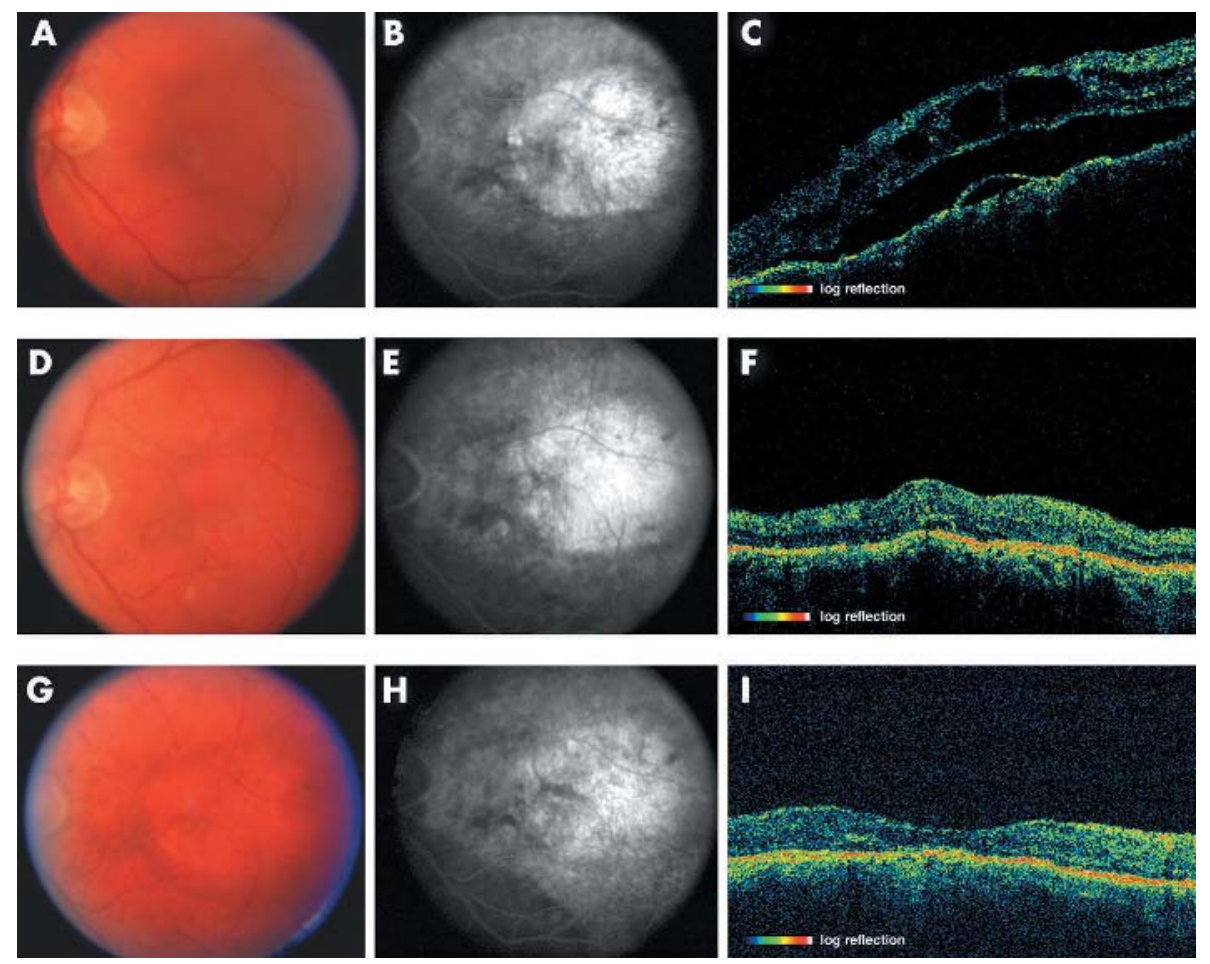

Figure 2 Colour photographs, midtransit phase fluorescein angiograms, and linear $6 \mathrm{~mm}$ optical coherence tomography scans through the fovea of patient 10 at baseline $(A, B, C)$,

3 months following first session (D, E,

$\mathrm{F})$, and 3 months following second session $(G, H, I)$ of ocular

photodynamic therapy showing improvement in retinal thickening, leakage, and foveal contour.
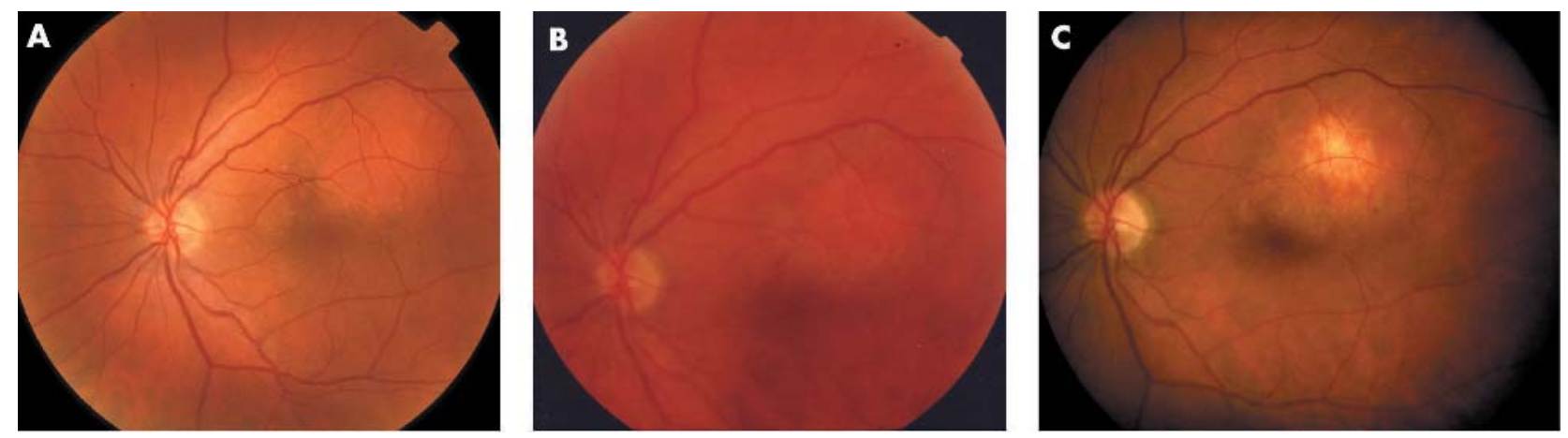

Figure 3 Fundus photograph of the left eye (patient 7) showing a circumscribed choroidal haemangioma before photodynamic therapy (A). The visual acuity was $20 / 100$. Three months following photodynamic therapy the tumour had regressed and visual acuity was $20 / 30$ (B). At 12 month follow up, an area of choroidal atrophy is evident with reduction of visual acuity to $20 / 100$ (C).

induced choroidal atrophy may be delayed in onset; therefore, long term observations on treated patients are necessary to fully evaluate the efficacy of PDT of circumscribed choroidal haemangioma.

\section{Authors' affiliations}

A D Singh, J E Sears, Department of Ophthalmic Oncology, Cole Eye Institute, Cleveland Clinic Foundation, Cleveland, $\mathrm{OH}$, USA

P K Kaiser, Clinical Research Center, Cole Eye Institute, Cleveland Clinic Foundation, Cleveland, Ohio, USA

J E Sears, Retina Service, Cole Eye Institute, Cleveland Clinic Foundation, Cleveland, $\mathrm{OH}$, USA

M Gupta, P A Rundle, I G Rennie, Department of Ophthalmology, Royal Hallamshire Hospital, Sheffield, UK

Correspondence to: Arun D Singh, MD, Department of Ophthalmic Oncology, Cole Eye Institute (i3-129), Cleveland Clinic Foundation, 9500 Euclid Avenue, Cleveland, OH 44195, USA; arunsingh@ eyetumors.com

Accepted for publication 18 March 2004

\section{REFERENCES}

1 Witschel H, Font RL. Hemangioma of the choroid. A clinicopathologic study of 71 cases and a review of the literature. Surv Ophthalmology 1976;20:415-31

2 Anand R, Augsburger JJ, Shields JA. Circumscribed choroidal hemangiomas Arch Ophthalmol 1989:107:1338-42.

3 Shields CL, Honavar SG, Shields JA, et al. Circumscribed choroidal hemangioma: clinical manifestations and factors predictive of visual outcome in 200 consecutive cases. Ophthalmology 2001;108:2237-48.

4 Sanborn GE, Augsburger JJ, Shields JA. Treatment of circumscribed choroidal hemangiomas. Ophthalmology 1982;89:1374-80.

5 Humphrey WT. Choroidal hemangioma: response to cryotherapy. Ann Ophthalmol 1979;11:100-4.

6 Schilling $\mathrm{H}$, Saverwein W, Lommatzsch A. Long term results after low dose ocular irradiation for choproidal hemangioma. Br J Ophthalmol 1997;81:267-73

7 Ritland JS, Eide N, Tasujo J. External beam irradiation therapy for choroidal hemangiomas. Visual and anatomical results after a dose of 20-25 Gy. Acto Ophthalmol Scand $2001 ; 79: 184-6$.

8 Kivela T, Tenhunen M, Joensuu T, et al. Stereotactic radiotherapy of symptomatic circumscribed choroidal hemangiomas. Ophthalmology 2003;110:1977-82.

9 Hannouche D, Frau E, Desjardins L, et al. Efficacy of proton therapy in circumscribed choroidal hemangiomas associated with serious retinal detachment. Ophthalmology 1997;104:1780-4. 
10 Kamal A, Watts AR, Rennie IG. Indocyanine green enhanced transpupillary thermotherapy of circumscribed choroidal hemangioma. Eye 2000;14:701-5.

11 Schmidt- Erfurth U, Tayyaba H. Mechanism of action of photodynamic therapy with vertoporfin for the treatment of age-related macular degeneration. Surv Ophthalmol 2000;45:195-213.

12 Barbazetto I, Schmidt-Erfurth U. Photodynamic therapy of choroidal hemangioma: two case reports. Graefes Arch Clin Exp Ophthalmol 2000;238:214-21.

13 Madreperla SA. Choroidal hemangioma treated with photodynamic therapy using verteporfin. Arch Ophthalmol 2001;119:1606-10.

14 Robertson DM. Photodynamic therapy for choroidal hemangioma associated with serous retinal detachment. Arch Ophthalmol 2002; 120:1155-61.

15 Schmidt-Erfurth UM, Michels S, Kusserow C, et al. Photodynamic therapy for symptomatic choroidal hemangioma: visual and anatomic results. Ophthalmology 2002; 109:2284-94.
16 Landau IM Steen B, Seregard S. Photodynamic therapy for circumscribed choroidal haemangioma. Acta Ophthalmol Scand 2002;80:531-6.

17 Jurklies B, Anastassiou G, Ortmans S, et al. Photodynamic therapy using verteporfin in circumscribed choroidal haemangioma. $\mathrm{Br} J$ Ophthalmol 2003:87:84-9.

18 Verbraak FD, Schlingemann RO, Keunen JE, et al. Longstanding symptomatic choroidal hemangioma managed with limited PDT as initial or salvage therapy. Graefes Arch Clin Exp Ophthalmol 2003;241:891-8.

19 Porrini G, Giovannini A, Amato G, et al. Photodynamic therapy of circumscribed choroidal hemangioma. Ophthalmology 2003;110:674-80.

20 Gupta M, Singh AD, Rundle PA, et al. Efficacy of photodynamic therapy in circumscribed choroidal haemangioma. Eye 2004;18:139-42.

21 Treatment of Age-Related Macular Degeneration with Photodynamic Therapy (TAP) Study Group. Photodynamic therapy of subfoveal choroidal neovascularization in age-related macular degeneration with verteporfin. neovascularization in age-related macular degeneration with verteporfin
One year results of 2 randomized clinical trials-TAP report 1 . Arch Ophthalmol 1999;117:1329-45. 